\title{
The Journal of Neurology
}

\section{and Psychopathology.}

Vo1. VI.

AUGUST, 1925.

No. 22 .

\section{Oríginal [Papers.}

\section{EPILEPSY AS A SYMPTOM OF DISSEMINATED SCLEROSIS.}

\section{By S. A. KINNIER WILSON AND HENRY J. MACBRIDE, Losdon.}

THE association of disseminated sclerosis and epilepsy, using the term in its widest sense, has been occasionally reported. References of this kind are few and far between, though the literature of both conditions is extensive. From a consideration of these sparse allusions the impression is gained that such cases have been regarded as being so rare as to preclude the possibility of any etiological deductions being drawn therefrom, or that the connection is thought to be no more than a casual coincidence. As we shall have occasion to point out immediately, Jacksonian attacks are reported more often, infrequent though they in fact are, than generalized epilepsy ; the latter, indeed, might be taken to be a genuine rarity in disseminated sclerosis if we judge by the extremely scanty references to it.

As long ago as 1881 James Ross, whose fine text-book of the diseases of the nervous system is undeservedly forgotten, made mention of apoplectiform or epileptiform seizures " in a small number of cases" of disseminated sclerosis; he regarded them as apparently analogous to the transient attacks characterizing general paralysis, developing in an acute way, with malaise and rise of temperature, and with convulsions and hemiplegia - all of a temporary kind. Ross, like all the older writers, uses the term 'epileptiform' in the strict sense given it by Hughlings Jackson, viz., unilateral, or, as we now say, Jacksonian. He does not allude to the possibility of generalized epilepsy being a symptom of disseminated sclerosis. Risien Russell, in Allbutt's System of 
Medicine (1910), states that " in a small percentage of cases apoplectiform or epileptiform seizures are met with." Gowers alludes to the former, but makes no mention of the latter.

In the otherwise very complete investigation of disseminated sclerosis conducted by the Association for Research in Nervous and Mental Diseases (New York, 1921) no allusion is made to the occurrence of epileptic symptoms in the disease. Jelliffe and White (1923), in their description of the same disease, say that " epileptiform attacks are much less often observed [than apoplectiform attacks] and usually speak against a multiple sclerosis, but they do occur . . . very frequently . . as Jacksonian attacks."

Other text-book authorities either repeat older statements or add information that substantiates but does not amplify. For instance, Schlesinger, in Curschmann's text-book, says that apoplectiform attacks, if associated with complete loss of consciousness, may be " accompanied in some cases by epileptiform seizures." Edwin Bramwell, in Osler and McCrae's System of Medicine (1910), under the heading of "Congestive and Epileptic Attacks," says he can recall but one instance in 150 personal cases (details not given), and speaks of them as being allied to the congestive attacks occurring in general paralysis. In a Symposium on Multiple Sclerosis (1908) Healy says : "much rarer are the so-called epileptiform attacks. These may possibly be of the Jacksonian type of seizure or partake of the nature of either major or minor epilepsy." There are references in Müller's well-known monograph (1904) to two cases with Jacksonian attacks. In a series of 206 cases of disseminated sclerosis collated by Frankl-Hochwart epileptic phenomena were noted in three.

Taking, next, the approach from the epileptic side, Aldren Turner (1907) does not refer to disseminated sclerosis among the organic lesions. of the brain which may give rise to so-called organic epilepsy, nor does Gowers in his book on epilepsy (1901), nor Oppenheim, although this writer says of disseminated sclerosis that "attacks corresponding to those of petit mal also occasionally occur, but in our experience these are very rare." In his latest edition (1923) the same distinguished authority says he has once seen the combination of the disease with "apparently genuine epilepsy."

It is better for our purpose to give a précis of such cases of the association as we have been able to discover in a scattered literature, with the proviso that we do not doubt others have been recorded with which we are not acquainted.

\section{SOME CASES FROM THE LITERATURE.}

A case is reported by Siebert, that of a young woman of twenty, whose symptoms began with epileptic attacks at intervals during two 
years. A status epilepticus then developed, of twelve hours' duration, and by the time this came to an end a left hemiplegia had established itself. Since the onset of the hemiplegia no further attacks took place. At a later date, nystagmus, spastic paraplegia, pallor of the temporal halves of the optic discs, amaurosis, etc., made the diagnosis of disseminated sclerosis a certainty. The Wassermann reaction in the blood was negative. Siebert says he has often seen the apoplectiform variety, but this is the only case with epileptic symptoms that has come under his notice.

Bruns and Stölting, discussing the eye symptoms of the disease, refer to a case (their Case III.), that of a woman of twenty-nine, whose symptoms commenced with ocular defects and ten years later formed a typical picture of disseminated sclerosis (spastic paraplegia, intentiontremor, pallor of the discs, etc.). Later, the patient developed a number of severe epileptic attacks with postepileptic stupor. No further details are given, and the account is closed with the negative comment that such attacks " nicht gerade häufig sind."

Marburg, whose paper on localized cerebral varieties of disseminated sclerosis is of importance in the present connection, cites some six cases of his own which presented symptoms resembling those of cerebral tumour. Among these are two (his Cases IV. and V.) that are of significance for our subject. The former is that of a woman of thirtythree, whose symptoms began with severe headache, and who suffered at fortnightly intervals from right-sided Jacksonian attacks, with vomiting and sometimes loss of consciousness. At a later stage the diagnosis of disseminated sclerosis became certain. The latter is that of a youth of seventeen, whose first symptom was a Jacksonian fit, which recurred and was succeeded by weakness of the left face; within three weeks the appearance of additional separate symptoms substantiated the diagnosis of acute disseminated sclerosis.

In a collection of cases operated on by Gussenbauer for cerebral tumour is one of no little interest. The patient was a man of thirtythree, whose illness began with some kind of fit (vomiting, unconsciousness, incontinence of fæces), which was followed by aphasia and paralysis of the right arm and leg. These symptoms cleared up within a fortnight, but a similar attack took place some months later, and was succeeded by a third and a fourth. The patient was eventually operated on ; no tumour was seen, but a diffuse cortical induration was found, supposed to be "eine Sklerose des Hirns." Later still, recurrent Jacksonian attacks took place, involving the right face and right arm, with or without loss of consciousness. Other symptoms which need not here be specified indicated that the condition was more widespread than the Jacksonian attacks would lead the observer to suppose. The case was lost sight of for a time; however, seven years later the patient died, 
when typical multiple sclerosis of the brain and cord was found at the autopsy.

Strümpell, on this topic, says : "much rarer than apoplectiform are epileptic attacks. We saw them repeatedly in a typical case (largely one-sided) with residual but rapidly disappearing hemiplegia. The nearer cause of all these attacks is unknown. They are not the result of grosser brain changes, but are due to functional conditions of paralysis or excitation."

Curschmann has recently reported a case of cortical epilepsy in disseminated sclerosis, the patient being a youth of twenty-one who suffered from frequent Jacksonian attacks (a dozen in a day) involving the face and tongue, without loss of consciousness. The seizures continued for ten weeks, during which time "the typical picture of multiple sclerosis developed."

Another recent case is that of Chartier, of which, however, the details are unfortunately meagre. The illness began by typical attacks of essential (idiopathic) epilepsy. "Later, the signs of disseminated sclerosis made their appearance, and now one finds the complete picture of that affection."

Other allusions we have been able to trace are too brief or scanty to constitute a real contribution. Hurst and Johnson analyzed fifty cases of disseminated sclerosis and mention one with "epileptiform convulsions." Ashley Mackintosh studied the modes of onset in eighty cases of the same disease and found three which began by an "apoplectiform attack," but it is not very clear from the descriptions of these whether an epileptic or epileptiform element was present. In one of them, " unconsciousness lasted for two weeks."

So far, the reader will see that differing types can be distinguished. (1) Jacksonian convulsions may usher in a paralytic condition, both of which pathological states may be transient; or the former may cease and the latter persist. (2) Jacksonian attacks may occur after the disease is established, and may be rather persistent ; they may implicate musculatures that are already paresed or paralysed. (3) Generalized epilepsy is by comparison distinctly more rare; it has been seen both before and after the appearance of the disseminated symptoms. These types, however, do not exhaust the possibilities, as we shall see.

It is known, of course, that so-called apoplectiform attacks may occur without convulsions, but these cases do not now concern us.

\section{PERSONAL CASES.}

For a number of years one of us has given close attention to the interrelation of disseminated sclerosis and epileptic phenomena, and a series of cases exhibiting both types of symptoms (disseminated and epileptic or epileptiform) have been kept under observation for a lengthy 
period. These cases we have recently called up for a fresh and detailed re-examination, the results of which will now be given in a succinct form.

CASE I.-Disseminated sclerosis; onset with generalized epileptic attacks.

G. S., female, age twenty-three.

History.-In 1917 the patient was working in her office, filing letters, when without any warning she fell down unconscious and an epileptic fit developed, with convulsions and tongue-biting. After the attack she felt drowsy, but soon made a good recovery, with neither headache nor weakness as a sequela. She had five fits during four months ; they came at gradually longer intervals, the second last being in May, 1918, and the last in February, 1920. She has had none since.

In January, 1921, the legs became weak, shaky, and tired; this lasted but a few days, and the patient felt perfectly well again. After a few months the leg weakness returned, disappearing again within a week. Since April, 1922, however, the limbs have been weak and stiff. In November, 1922, diplopia occurred, for about four weeks. Since January, 1923, shakiness of the arms, paræsthesiæ, dysuria and occasional incontinence have been noted.

Present Condition.-Slight temporal pallor of optic dises ; nystagmus on lateral deviation to right and left ; spastic paraplegia ; mild intentiontremor; exaggerated deep reflexes; double ankle clonus; absent abdominal reflexes; double extensor response. Wassermann test in blood, negative.

CASE II.-Disseminated sclerosis; onset with generalized epileptic fits with local commencement; later, Jacksonian attacks only.

J. F., male, age thirty-three.

History.-About thirteen years ago patient was sitting on a bench when, without any warning, the right leg began to 'quiver' and a few seconds later he lost consciousness, was convulsed generally, bit his tongue and passed water involuntarily. There was neither headache nor weakness after the fit. From 1912 to 1915 he had some six similar fits, with local commencement and becoming generalized.

In 1915 these attacks changed in character somewhat; the 'quivering' started in the right foot and spread up the leg; reachingt the shoulder, it spread down the right arm, being there associated with numbness. After some of the attacks the right arm was more or less paralyzed for a few minutes, and the right leg felt weak. There has been no incontinence or tongue-biting in these attacks, the patient being conscious throughout. They are now very rare, averaging less than three in a year.

Since 1915 the right leg has steadily become weaker and slightly wasted, and the right arm has also weakened, but to a less extent. 
Present Condition.-Pallor of both optic discs; well-marked nystagmus on lateral deviation to right and left; slight weakness of the right lower face; defective sense of position and of passive movement in right arm and in both legs, right worse than left ; incoordination in right arm ; no astereognosis ; weakness and slight spasticity of right leg; weakness at left ankle; hemiplegic gait ; all deep reflexes active, and increased on the right; ankle clonus right; plantar reflexes both flexor (not good). Wassermann test in blood, negative.

CASE III.-Disseminated sclerosis ; generalized epileptic fits at long intervals.

E. B., female, age forty-seven.

History.-Some twenty years ago paralysis of right side of face and diplopia, the duration of these symptoms being six weeks. Eighteen years ago paræsthesiæ of the arms and hands, which soon cleared up. About fifteen years ago difficulty in walking, and, two years later, ' partial paralysis,' which further questioning shows to have consisted of considerable weakness and 'loss of use' of all the limbs. Since that date variable weakness in limbs, more particularly in the legs. Apparently little or no bladder or rectal trouble.

During these twenty years patient has had some six or seven typical epileptic fits, at long intervals of two or three years. To these fits there has been no warning; they have been characterized by generalized convulsions, with tongue-biting and involuntary micturition. No transient weakness has followed them, nor any aggravation of existing paresis. The last attack was some eighteen months ago.

Present Condition.-Well-marked nystagmus in all directions; pronounced temporal pallor of discs, especially on the left; ataxic paraplegia; exaggerated deep reflexes; absent abdominal reflexes; double extensor response. Wassermann test in blood, negative.

CASE IV.-Disseminated sclerosis ; many general epileptic fits at an early stage, and subsequent disappearance of these.

L. La., female, age thirty-five.

History.-Some fourteen years ago (1911), at the age of twenty-one, the patient lost all feeling in the left hand; it was numb and 'dead,' and some objective change must have been present, for she remarked that in sewing she sometimes " sewed things on to her skin " and did not notice any pain. The numbness vanished after about one year, and she felt perfectly well.

In 1914 she began to suffer from typical epileptic fits. On the first occasion, no warning being experienced, she fell down unconscious when in the act of preparing supper, was convulsed and incontinent of urine, but did not bite her tongue. After the attack she had a headache and felt generally 'weak.' The second fit was three months later, and was 
similar, but more severe. Some six weeks later they increased in frequency and continued for no less than a year, averaging two or three attacks every week. The features of general convulsions, cyanosis, and vesical incontinence were always present, but no paresis was noticed after any one of them. Thereafter the fits gradually lessened, and have now entirely disappeared for about five years, i.e., since about 1920.

In 1916, while the epilepsy was continuing in moderate degree, numbness and transient weakness of the left leg came on. At variable intervals, ever since, the left leg has been weak and dragging, and on occasion apt to "trip her up" if she does not exercise care. Frequent paræsthesiæ of both legs have been noticed. About two or three weeks ago weakness of the right leg came on for the first time.

Five years ago definite transient amaurosis of the left eye was noted.

Present Condition.-Pronounced pallor of both optic discs, more marked on the temporal side in the left eye ; nystagmus, horizontal and with a slight tendency to rotation, present in both eyes on lateral conjugate deviation ; delay in appreciation of pin-prick irregularly over limbs, especially on the left ; moderate spastic ataxia of legs, with some unsteadiness and some intention-tremor in the knee-heel test; some incoordination in finger-nose test on right, not left ; brisk deep reflexes ; absent abdominals; plantar reflex flexor on right, extensor on left; sphincters, both precipitancy and incontinence on occasion. Wassermann test in blood, negative.

CASE V.-Disseminated sclerosis; Jacksonian fits, and generalized epilepsy with local commencement, for sixteen years; appearance of disseminated symptoms only within the last year or two.

L. Le., female, age thirty-four.

History.-At the age of sixteen, when the patient was standing at her garden gate, she suddenly felt a peculiar feeling in the right arm, "as if she had knocked her funny bone." At the same moment the right arm drew up, then the right leg and the right face twitched, and at this point she fell to the ground unconscious, was generally convulsed, bit her tongue, and was incontinent of urine. Transient slight headache, drowsiness, and weakness foilowed this fit. Three years later, at the age of nineteen, an exactly similar fit took place. When six months pregnant, at the age of twenty-two, she had a third fit, and a fourth six months after the confinement. When twenty-eight years old she had three in six months; when thirty, three again within a few months of each other ; when thirty-two, again three or four in the course of some months. This year (1925) the patient (age thirty-four) has had five up to date.

During the last year or two the fits have somewhat altered. There 
is now a longer aura, the patient having time to run and call some one to assist her. Tingling, "like electricity," starts in the fingers of the right hand and travels up the arm to the shoulder; just as it approaches the latter the arm is drawn up in a convulsive movement, and as it spreads down the trunk the right leg is similarly drawn up in a convulsion. Frequently the fit now does not become generalized, there being no tongue-biting in the last half-dozen fits and no incontinence in the last five.

For about eighteen months, more or less, the patient has found that the right hand is weak and awkward in fine movements, and numbness has been experienced in the fingers on that side. After the recent fits she has noticed she is "sort of drunken" in speech and gait. Recently, in cold weather there has been definite difficulty in controlling the vesical sphincter. Recently, too, emotional overaction (laughing) has become a distinct symptom.

Present Condition.-Pallor of both dises in the temporal halves, particularly on the right; definite and well-sustained nystagmus on conjugate lateral deviation to right and left, with occasionally a rotatory element; no discoverable weakness in either arms or legs, yet a wellmarked double extensor response is constantly found, and the abdominals are absent. Wassermann test in blood, negative.

CASE VI.-Disseminated sclerosis of eleven years' duration; general epileptic fits on an average once a year throughout the whole illness.

A. H., female, age twenty-four.

History.-At the age of thirteen patient began to suffer from numbness in the left leg and arm, which increased in degree for an indefinite time and disappeared after about three years. At the age of sixteen she became unsteady on her legs, and began to lose control of the left arm. Three years later diplopia developed, and a year afterwards incontinence of urine. Tremors in the arms made their appearance about this time.

Throughout the whole time the patient has had typical generalized epileptic attacks on an average once every year, with convulsions, cyanosis, and involuntary micturition. The aura has been "flashes before the eyes."

Present Condition.-Marked pallor of discs; ophthalmoplegia ; nystagmus in all directions; intention-tremors; ataxic paraplegia; pronounced weakness of limbs; exaggerated deep reflexes ; rectus and ankle clonus on both sides ; double extensor response ; loss of sphincter control. The Wassermann test was not made in this case.

CASE VII.-Disseminated sclerosis of fifteen years' duration ; general epileptic seizures at irregular intervals from the beginning.

B. D., female, age forty-four. 
History.-About fifteen years ago patient's illness began with diplopia and strabismus ; since then both motor and sensory symptoms have made their appearance. For several years the gait has been uncertain and dragging; for one or more years bladder control has been weakening.

At long and irregular intervals the patient has suffered from characteristic generalized epilepsy, with unconsciousness, convulsions, cyanosis, tongue-biting, and involuntary micturition ; occasionally the attacks have occurred at short intervals.

Present Condition.-Well-marked nystagmus; pronounced pallor of optic discs ; incoordination in all limbs ; intention-tremors ; slightly staccato articulation; emotional over-action; ataxic paraplegia; exaggerated deep reflexes; double extensor response. Wassermann test in blood, negative.

\section{CLINICAL TYPES AND VARIETIES.}

We have been able to collect some eight cases from the literature where the association of epilepsy or epileptiform attacks with disseminated sclerosis has been recorded. To these we are able to add seven personal cases, making a total of fifteen. As remarked above, we do not doubt that other reported cases have escaped our search, and we know from personal communications that other neurologists have met with the combination of the two in their hospital or private practice, although such instances have not been published.

It cannot be said, then, that epilepsy is excessively rare as a symptom in disseminated sclerosis ; it is, however, undoubtedly infrequent. It is difficult for us to estimate how many examples of the affection we have jointly seen; certainly the number runs into many hundreds, for the disease is common in England, and at the National Hospital it is seen by scores of cases every year. Since we have collected only seven certain cases of our own, out of ' many hundreds,' no other conclusion is permissible than that epilepsy is one of the rare symptoms, but its interest is out of proportion to its rarity.

A clear distinction should be drawn, we consider, between (1) the epileptiform and (2) the epileptic variety.

1. Epileptiform Attacks.-To this group belong our Cases Nos. II. and V., and the cases recorded by Siebert, Marburg (his Cases IV. and V.), Gussenbauer, Strümpell and Curschmann, a total of eight. These, moreover, may in their turn clearly be subdivided. Thus : $(a)$ the very first symptom of a developing disseminated sclerosis may be Jacksonian attacks followed by paresis or paralysis, transient or persisting (Siebert, Marburg, Gussenbauer, Strümpell); (b) Jacksonian attacks may occur at the outset, and for years, without any weakness whatever as a sequel (our Case No. II.). Our Case V. might be included indifferently under 
either $(a)$ or $(b)$, for the 'weakness' occurred only after the first attack and was altogether trifling; after many subsequent epileptiform fits no weakness has been discoverable. We have not seen, nor have we found in the literature, any case in which Jacksonian attacks have begun after the symptoms of disseminated sclerosis have become well established, although in the case of Gussenbauer and in our Cases Nos. II. and V. -they have continued in these circumstances. Conversely, the Jacksonian fits ceased in Siebert's case after paralysis developed. It is probably not justifiable to make a separate sub-group of those cases in which, as an initial symptom, generalized epileptic attacks with definite local commencement have occurred; we have classed such with the Jacksonian cases. We direct attention to the fact, none the less, that in our Cases Nos. II. and V. the generalized attacks with local commencement have gradually become slighter, that is, more typically Jacksonian and limited. Curschmann's case should be classed under $(b)$ above, but the details are somewhat scanty.

2. Epileptic Attacks.-In this group the only recorded cases we have obtained are those of Chartier and of Bruns and Stölting; we are able to add our Cases Nos. I., III., IV., VI., and VII. Chartier's case began with generalized epilepsy a considerable period before any symptoms of disseminated sclerosis made their appearance. In this respect it is analogous to our Case No. I. Our other cases of this group have been characterized either by occasional epileptic fits throughout the whole course of the disease (Cases Nos. III., VI., and VII.), or by similar fits for a period only (Case No. IV.). Apparently the case of Bruns and Stölting resembles this latter case of ours.

3. Only one case has come under our observation in which the diagnosis of petit mal is possible. As we are rather doubtful of it, petit mal attacks not having been personally seen, we have not cared to give the details. From the description furnished us, however, we may simply state that 'turns' occurred during which the patient was "unable to speak for several seconds," and then "went on again as if nothing had happened."

4. We have also a solitary case of disseminated sclerosis in which a condition that we consider belongs to the rarity 'epilepsia partialis continua' has been a prominent symptom.

CASE VIII.-Disseminated sclerosis with 'epilepsia partialis continua.'

F. P., male, age forty-one.

The original symptoms of disseminated sclerosis date back some fourteen years or more, and are now fully developed (nystagmus, tremors, emotional overaction, ataxic paraplegia, absent abdominals, double plantar extensors, Wassermann test negative in blood). 
Some four weeks before admission the patient had a typical epileptic fit, which commenced by clenching of the right hand, with a "funny sensation" that ran up the arm. "It felt as if you were winding up a clock in the arm." Ever since, the right arm and hand have been the seat of continual irregular clonic twitches; they are not uniform in rate or force, and in character are indicative of cortical irritation. The limb is definitely paresed.

\section{PATHOGENESIS.}

Obviously, more than one theory of pathogenesis can be entertained.

1. It might be held, with some show of reason, that the association of epilepsy with disseminated sclerosis is incidental, accidental, and of no significance.

To support this point of view all that is necessary is to emphasize the rarity of epileptic phenomena in this very common nervous disease, and, secondly, to stress the fact that even in the small number of cases such diversity of epileptic symptoms occurs as to veto the probability of any causal connection between the two.

This line of reasoning, however, does not appeal to us. Epilepsy is a cortical symptom, and among the great group of disseminated cases those with purely cortical symptoms form but a relatively small minority. Considered, further, from the neuropathological standpoint, a pure cortical localization of the disseminated lesions is not very common, in comparison, that is to say, with the frequent ependymal, periventricular, mesencephalic, ponto-cerebellar, and spinal sites that they occupy. We might buttress our argument with a reference to the relative rarity of the symptoms of toxic psychosis in the disease, yet such do occur on occasion. 'Mental' symptoms develop, if at all, usually at later stages, when the morbid process is invading the brain widely, whereas the epileptic phenomena, as we have seen, may be an early sign of the disease, and are bound to remain uncommon, in view of what has been said of cortical symptoms clinically and of cortical lesions pathologically.

Approaching this question from another angle, we wish next to underline the fact that in no single one of our cases have we obtained a family history of epilepsy, though in every instance this matter has been gone into with care. It is quite true that the strictures recently passed by Myerson on the heredo-familial theory of epilepsy have much to justify them, and the experience of one of us over a long period in the handling of hundreds of epileptic cases undoubtedly goes to support his view, that " epilepsy is mainly an affair of the individual and not of the stock." If this is so, then it stands to reason that the appearance of epileptic symptoms in a patient who is suffering, or is about to suffer (as the sequel shows), from an organic nervous affection 
so definite as disseminated sclerosis, may legitimately be set down to the change effected thereby on normal cortical function. We do not seek aid from any obscure theory that the disseminated patient who develops fits is somehow 'predisposed'; we hold, on the contrary, that the fits are somehow the direct or indirect result of the disseminated disease.

2. Taking the Jacksonian cases first, the observer must be struck with the resemblance of some of the cases to those of ordinary, sporadic encephalitis, such as every neurologist is familiar with. The patient becomes ill with cerebral symptoms, develops fits (Jacksonian, or general, with local commencement), and subsequently shows a paresis on the affected side. Jacksonian fits may recur thereafter, implicating the already affected musculature. So close is the resemblance, on occasion, to the encephalitis which precedes the "infantile cerebral hemiplegia with fits " type that it is legitimate to postulate for these cases a patch of encephalitis, which histologically belongs, however, to the disease called disseminated sclerosis. We do not require to remind the reader how much evidence has accumulated to prove, or at least to suggest, that the early stages of the sclerosis are akin to encephalitis.

Again, other instances give a picture reminiscent of the transient 'attacks' in general paralysis, and the pathological process underlying these can justly be included under the term encephalitis if the latter is employed in a wide sense. Unfortunately, we are compelled to argue here solely by analogy, for, as far as we know, in none of the recorded cases of disseminated sclerosis with epilepsy that have been subjected to subsequent pathological investigation has any detailed attempt been made to correlate the clinical and the pathological data.

We are not at present concerned with the mechanism of production of the Jacksonian attacks, for this is a quite separate problem appertaining to all Jacksonian cases, whether in the rare disseminated group or not, and leading, indeed, into a field which is even more speculative than the pathological.

For the Jacksonian fits, then, we postulate an underlying basis of actual cortical alteration, and we presume this is constituted by some encephalitic patch, with its accompanying modification of parenchymatous tissue elements.

3. The majority of our personal cases, on the other hand, have been examples of the appearance of generalized epileptic seizures in the course of the disease; in some, these have been the first symptom, and have preceded by years the appearance of the disseminated symptoms; in others, the course of the disease has been marked at intervals by the development of epileptic fits.

It is not easy, we submit, to envisage any other pathogenic process for these attacks than one which is toxic or toxi-infective. No structural basis, it seems, will explain their appearance as an initial 
symptom, and their continuance for a year or more, while objective signs of the disease are still completely awanting. Their development cannot feasibly be set down to any early hydrocephalic condition, we consider, nor have we in any case been able to find a basis for them in disease or dysfunction of some other somatic system, such as, for instance, the urinary. If we allow ourselves to be impressed by the evidence of our Case No. I. here reported, and of that recorded by Chartier, it would appear that the disease may 'incubate' over a long period before giving rise to somatic manifestations.

The problem of the appearance of general epileptic fits as an initial or early symptom of disseminated sclerosis is analogous to that furnished by the similar, and rare, appearance of fits as a prodromal indication of cerebral tumour. We are equally in the dark as to the exact pathogenesis of general convulsions in these cerebral tumour cases, before the objective manifestations of tumour can be determined.

Since none of our own cases have come to autopsy the contribution we can make is purely clinical; we are content rather to state the question than to attempt to solve it in what, after all, can only be a conjectural fashien. Epileptiform or epileptic seizures must be accepted definitely as occasional symptoms of disseminated sclerosis, and in this respect the disease falls in line with other cerebral toxi-infective states.

\section{REFERENCES.}

1 Ross, James, The Diseases of the Nervous System, 2nd ed., 1883, vol. ii, 760 .

2 Russelu, Risien, System of Medicine (Albutt and Rolleston), 2nd ed., 1910, vol. vii, 827 .

3 Jelliffe, S. E., and White, W. A., Diseases of the Nervous System, 4th ed., 1923, 571.

4 Schlesinger, Hermann, Curschmann's Text-book on Nervous Diseases, English ed., 1915, vol. i, 345.

5 BRAmwell, EDwIN, System of Medicine (Osler and McCrae), 1910, vol. vii, 156.

6 Healy, William, Illinois Med. Jour., August, 1908.

7 FrankL-Hochwart, voN, quoted by Bramwell (5).

8 OPPENHEIm, H., Lehrbuch d. Nervenkrankheiten, 7th ed., 1923, vol. i, 479.

SIEBERT, Deut. Zeits. f. Nervenheilk., 1918, Ix, 260.

10 Bruns and Stölting, Zeits. f. Augenheilk., 1900, iii, 1.

11 Marburg, OtTo, Deut. Zeits. f. Nerveriheilk., 1921, lxviii, 27.

12 GUSSENBAUER, Wien. klin. Woch., 1902, xv, 175, 964.

13 STRüMPELL, quoted by Siebert (9).

14 CurschmanN, Klin. Woch., 1922, i, 71.

15 Chartier, L'Encéphale, 1922, xvii, 187.

16 Hurst, A. F., and Johnson, W., Guy's Hospital Reports, lxvi, 109.

17 Mackintosh, A. W., Rev. of Neurol. and Psychiat., 1903, i, 73. 